\title{
Digital assessment of individual engineering assignments in mass courses
}

Dr Majid Aleyaasin Lecturer, Fraser Noble Building, School of Engineering

University of Aberdeen, Aberdeen AB24 3UE ,United Kingdom

Telephone: +44 (0)1224 273497 E-mail:m.aleyaasin@abdn.ac.uk

ORCID 0000-0002-4400-6338

In this article a digitally assisted tool, that uses a master computer program for a particular assignment, and enables quick and semi-automatic assessment is introduced . Since the data allocated to each student is different from the other classmates, acquiring the correct results depends on the sole effort of the student.

The master program will produces the correct results in a tabular format. Then student is asked to provide his/her results with same format, and submit the work to the course web site. The marker assesses the work by running the master program and observing the correct results. In last step the student's result with the same format will be compared with the correct results and an appropriate feedback will be provided for that student.

In the first experiment 300 undergraduate students with different mathematical knowledge, have been asked to find the acceptable ranges of a gear ratios for a particular electromechanical device and submit their results. In the $2^{\text {nd }}$ experiment 40 postgraduate students have been, with different engineering and science degrees, asked to find the optimal passive fire protection system for the structural elements.

It is concluded that for strengthening the innovation in students, apart from group projects, the individual assignments are also necessary. The digital method described in this paper, can reduce the assessment time substantially, and also provides appropriate feedback for each student. Future applications and improvements are discussed and commented upon.

Keywords: Digital, Assessment, Assignment, Engineering Design 


\section{Introduction}

There are substantial literature on using computer and digital technology in engineering education. An example for computer and network assisted teaching is described in [1]. Sometimes the effect of computer in teaching is substantial such that some tools are developed [2] for particular courses. Another branch of computer application is the procedure for web assisted virtual experimentation as explained in [3]. In special circumstances digital technology can cause perception enhancement in students [4].

Engineering assignments can be project based learning of any course either in undergraduate or post graduate study. Digitally assisted methods for supervision can boost the leaning outcome [5]. Such methods can be extended to complicated issues like digital product dissection in engineering design courses [6]. Moreover, communication skills and presentation can also be strengthened as explained in many references like [7].

In classes with large number of students, management of the course will be difficult, and digital technology can increase efficiency of the assessment procedure, substantially [8] . In deep assessment via assignment scenario, the leadership and problem solving capability of groups of students for the projects can be monitored manually [9] due of small number of groups . However, in mass courses which need individual assignments, this will be a challenge, that only computer assisted technology can overcome.

Herein the author with two decades of teaching experience in engineering, believes that group projects and their assessment is necessary for an engineer, since he/she will work with a team in future industrial careers . However, the authors believes that individual assignments are also required to motivate students toward independent thinking as well . In order to assess the effort of the individual student in mass classes, with high number students, the help of digital technology will be required. 
In this paper, Individual assignments are those that assigned to one student only and he /she will submit the assignment via the course web site as a sole author . In the courses with massive number of students, manual individual assessment will be a formidable task. In order to assess the submitted work quickly, a master computer program is developed for a particular assignment that provides the correct results in a suggested format. Thereafter, students are asked to prepare the report and show the results with the suggested format, either by a computer program or by a manual calculations. Finally, the assessor can compare the student's results with correct results and provide the feedback quickly.

The idea of automatic assessment, initially introduced for computer based assignments, [10] and later used to check the MATLAB and Simulink models and codes [11]. Recently research is going on to test the MATLAB codes in first year computation courses with large number of students [12]. However, automatic assessment of engineering assignments, whether, students is done it by computer or not, is the idea author's and he has implemented in many courses during his lectureship career in Aberdeen University school of engineering.

The first example that will be discussed is a short assignment that $2^{\text {nd }}$ year engineering students do, for the course coded EG2503, "Electrical and Mechanical Systems". During previous years up to 330 students, attended in the course each semester, in which they do several assignments. One of the assignments that is coordinated by the author is digitally assessed and will be discussed in the next section.

The $2^{\text {nd }}$ example is a relatively long assignment, that postgraduate students in M.Sc. safety engineering and other disciplines do for the course coded EG5071 "Fire and Explosion Engineering". During past years up to 50 students in each semester attended, and each student is provided with an individual data, to do their assignment. The master computer program will print the correct results, when the data of any students is plugged in. The conclusions and future 
applications of this digitally assessed procedure is discussed and commented upon. The novelty in both case studies is "semi-automatic assessment in situation when each student in the class allocated a unique data and he/she submits his/her own results to the assessor".

\section{Experience in an undergraduate course}

In this short assignment the in the course EG2503 "Electrical and Mechanical Systems", students asked to find the appropriate range for the gear ratio of the following system as (electro gearbox) shown in in Figure 1.

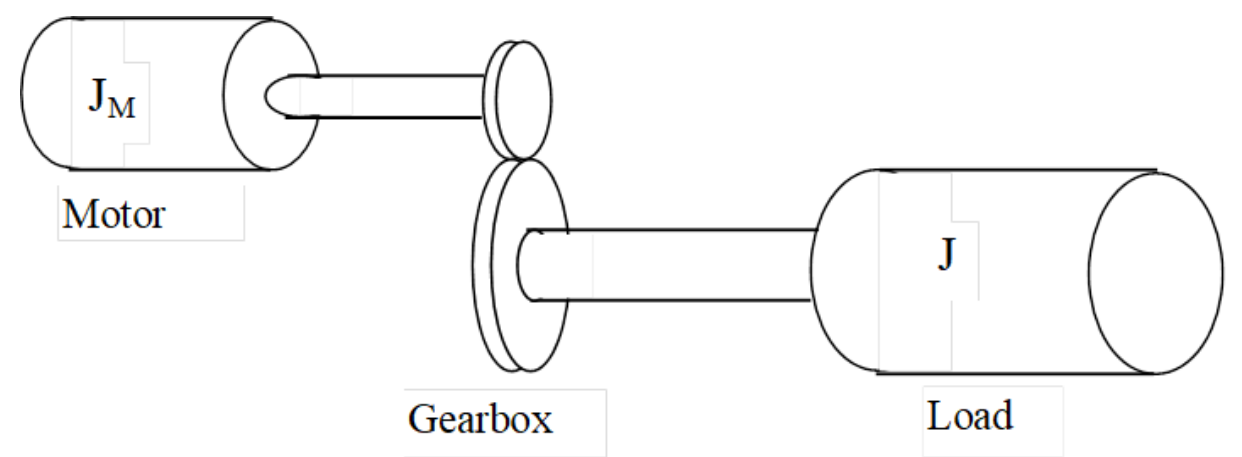

Figure 1 Proposed Drive Arrangement

The governing equation for the drive torque is given during lectures which is:

$$
T_{D}=\underbrace{\left(J_{l}+N^{2} J_{m}\right)}_{J_{e}} \alpha_{L}+\underbrace{\left(f \omega_{L}+T_{s}\right)}_{T_{L}}
$$

The data that are given to all students are:

Load inertia, $\mathrm{J}_{1} \quad 1.3 \times 10^{-3} \quad \mathrm{~kg} \cdot \mathrm{m}^{2}$

Viscous friction coefficient, $\mathrm{f}, \quad 9.5510^{-9} \quad$ N.m.s/rad

Motor inertia, $\mathrm{J}_{\mathrm{m}} \quad 1.3 \times 10^{-7} \quad \mathrm{kgm}^{2}$

For the remaining data, students are asked to look at the allocated data in front of their name in the course web site. They are :

Static friction torque, $\mathrm{T}_{\mathrm{s}} \quad$ see allocated data Maximum output shaft acceleration, $\alpha_{\operatorname{lmax}}$ see allocated data

The rotational speed dependent motor torque $T_{m}$ is given to all student via figure 2 : 


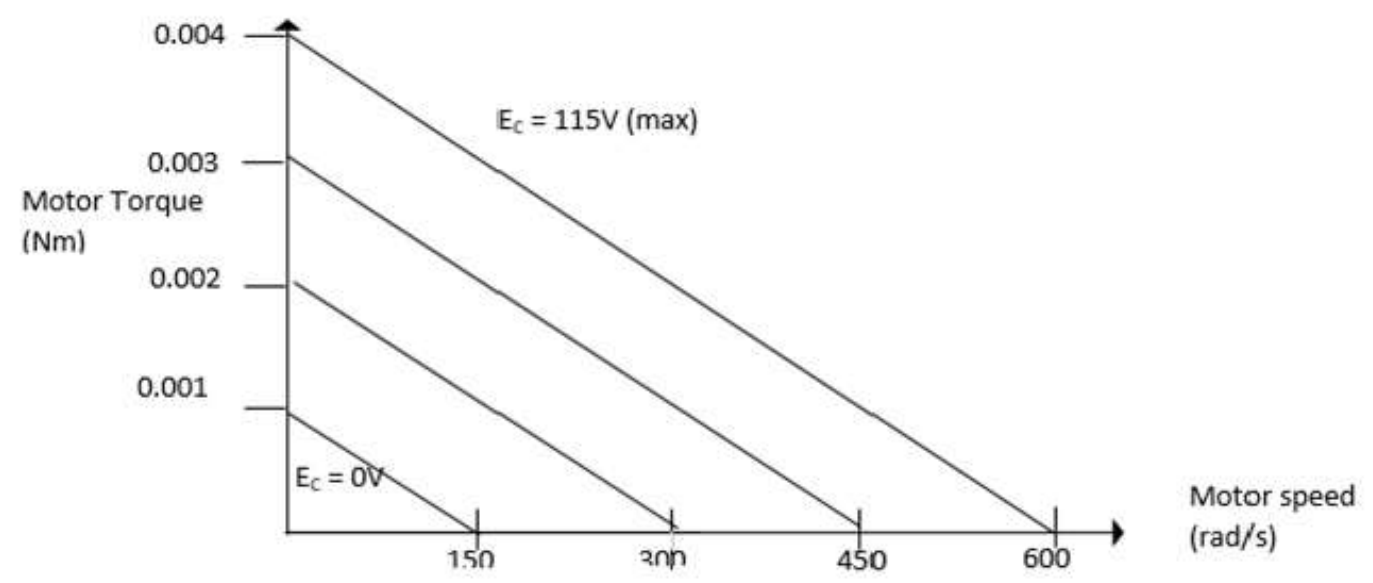

Figure 2 Torque-Speed Characteristics for AC Servomotor

Part of the allocated data given to the student in which the name of students are removed are shown in figure 3.

\begin{tabular}{|l|l|l|l|l|}
\hline Surname & First name & & $T_{\mathrm{s}}$ in N.m. & $\begin{array}{l}\alpha_{\max } \\
\text { in rad } / \mathrm{s}^{2}\end{array}$ \\
\hline & & & 0.02 & 9 \\
\hline & & & 0.0210 & 9.5 \\
\hline & & & 0.023 & 10 \\
\hline & & & 0.024 & 10.5 \\
\hline & & & 0.026 & 11 \\
\hline & & & 0.026 & 11.5 \\
\hline & & & 0.028 & 12 \\
\hline & & & 0.037 & 12.5 \\
\hline & & & 0.031 & 13 \\
\hline & & & 0.039 & 13.5 \\
\hline
\end{tabular}

Figure 3 : Sample of allocated data to individual students

The individual students will complete the assignment in two 3 hours sessions. In the first session ( week 1) they develop a MATLAB program to produce figure 4 . In the $2^{\text {nd }}$ session (week-2) they carry out theoretical discussions to justify the results provided by computer program in week 1 . This enables the graph they have produced to be titled, with the numbers. 
In each week they have been given assignment instructions in the computer lab and the demonstrators can also answer to their questions. All the activities are carried out in big classrooms up to 50 students each day and, the end they will submit the reports to the course web site.

A master program is written by the assessor that contains all general data, and also accepts individual data for each student. For example if we enter the last row data in figure $3, \mathrm{~T}_{\mathrm{s}}=0.039$ N.m. and $\alpha_{\max }=13.5 \mathrm{rad} / \mathrm{s}^{2}$ that is allocated to a particular student, the master program will provide the following results like figure 4 .

\section{gear ratio range $\mathrm{N}>9.75$ and $\mathrm{N}<14.23$ chosen $\mathrm{Nd}=11.99$}

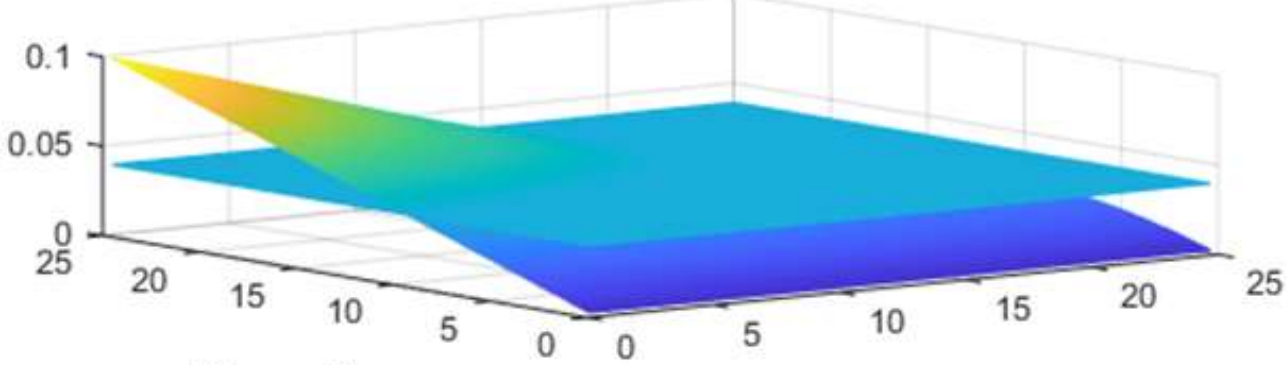

Gear ratio

load angular velocity $\mathrm{rad} / \mathrm{s}$

\section{then steady speed is $89 \mathrm{rpm}$ also $\mathrm{N}>2264$ is not feasible}

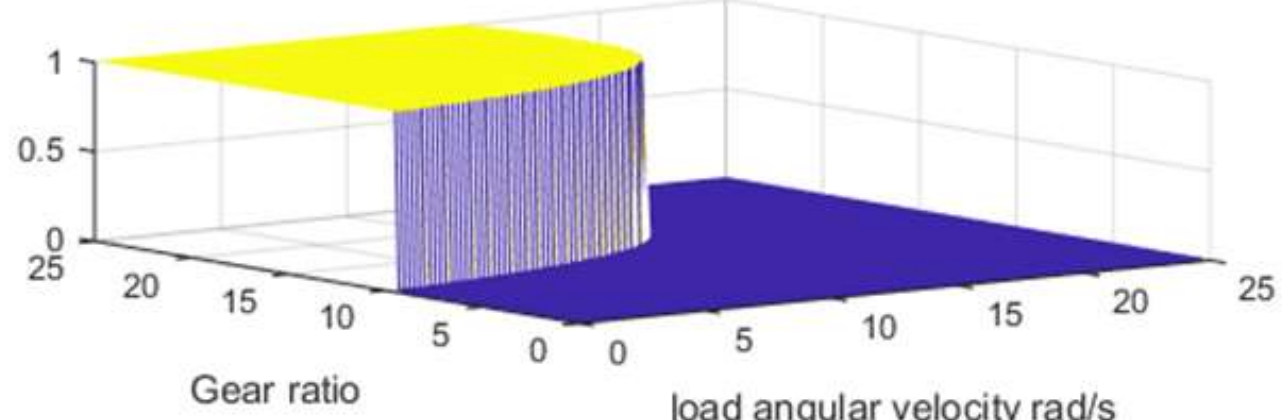

Gear ratio

load angular velocity $\mathrm{rad} / \mathrm{s}$

Figure 4: Printed results by master program for $\mathrm{T}_{\mathrm{s}}=0.039$ N.m. and $\alpha_{\max }=13.5 \mathrm{rad} / \mathrm{s}^{2}$

The assessor then looks at the result provided by the student with the same format, and find if he/she have found the correct results and then prepares a quick feedback. 
We will teach the student, how provide the first graph by MATLAB, but they can produce with any other program if they want. By considering the load angular velocity in the range $0.4 \leq \omega_{l} \leq 25 \mathrm{rad} / \mathrm{s}$, and the gear ratio in the range $0.4 \leq N \leq 25$, students can calculate the load torque, motor torque and the drive torque of the gear box, in 15129 steady state situation in the program by using these the formulas:

$$
T_{L}=f \omega_{l}+T_{s} \quad T_{m}=-m \omega_{m}+C \quad T_{D}=N T_{m}
$$

Using the commands "for" " "if" and "plot" in MATLAB they can produce the graph in the figure 4 easily by storing the data for $T_{L}$ and $T_{D}$. In the first week from figure 4 , they can observe that in gear ratios that $T_{D}>T_{L}$ gearbox works, whereas for in gear ratios that $T_{D}<T_{L}$ gearbox fails. Moreover, the boundary between acceptance and failure $T_{D}=T_{L}$ results steady state speed, as shown in bottom of figure 4.

In the week 2, students study the theory of the calculations by substituting (2) in (1) to find

$$
\alpha_{l}=\frac{\left(-m \omega_{m}+C\right) N-\left(f \omega_{l}+T_{s}\right)}{\left(J_{l}+N^{2} J_{m}\right)}
$$

Next they study the starting from zero speed and considering $\alpha_{l} \leq \alpha_{\max }$ and setting $\omega_{l}=0$ in (2) it leads to following inequality:

$$
g(N)=N^{2} J_{m} \alpha_{\max }-C N+T_{s}+J_{l} \alpha_{\max } \geq 0
$$

The roots of the quadratic polynomial in (4) are $N_{1}$ and $N_{2}$ to satisfy $0 \leq \alpha_{l} \leq \alpha_{\max }$ the gear ratio should be $\frac{T_{s}}{C} \leq N<N_{1}$ and the solution $N>N_{2}$ will not be feasible because of high gear ratio. Thereafter they choose the average as the gear ratio :

$$
N_{d}=\frac{T_{s}}{2 C}+\frac{N_{1}}{2}
$$

By which the steady state rpm will be:

$$
r p m_{s s}=\frac{\left(T_{s}-C N_{d}\right) 30}{-\left(m N_{d}^{2}+f\right) \pi}
$$




\section{Experience in a postgraduate course}

In this long assignment the in the course EG5071 "Fire and Explosion Engineering", students Have asked to find the minimum insulation thickness, to protect a steel structural member against the fire and schematic shown in figure 5 .

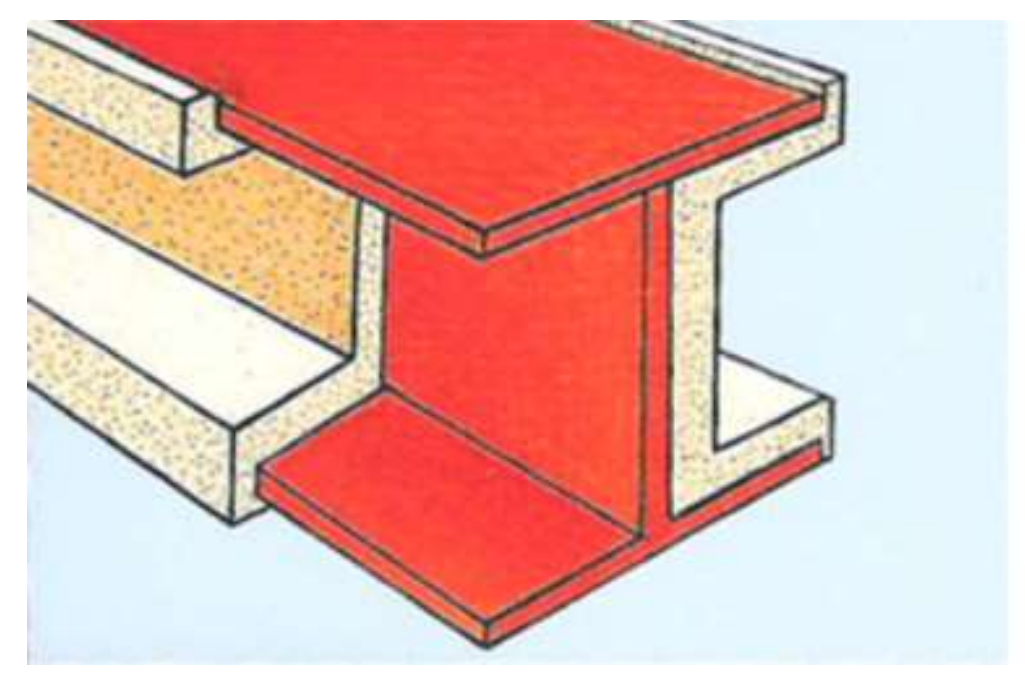

Figure 5: I beam with insulation

All students have been given following information including the fire curve or the temperature history in hydrocarbon pool fire via this equation :

$$
T_{g}=T_{o}+1080\left(1-0.325 e^{-\frac{0.167 t}{60}}-0.675 e^{-\frac{2.5 t}{60}}\right)
$$

where $t$ is expressed in sec. Students need to find minimum insulation thickness for a I beams to resist the fire for 30 minutes. This means after 30 minutes exposed to fire the temperature in steel should not exceed $350^{\circ}$ C. The specific heat capacity of insulator is $C_{i}=1100 \mathrm{~J} / \mathrm{Kg} \cdot \mathrm{C}^{0}$ and the density is $\rho_{i}=300 \mathrm{Kg} / \mathrm{m}^{3}$. For the steel the specific heat capacity is $C_{s}=600 \mathrm{~J} / \mathrm{Kg} .{ }^{0} \mathrm{C}$ and the density is $\rho_{s}=7850 \mathrm{Kg} / \mathrm{m}^{3}$. The ambient temperature is $20^{\circ} \mathrm{C}$. The governing difference equation is: 


$$
\Delta T_{s}=\frac{U}{c_{s} \rho_{s}} \cdot \frac{A}{V} \cdot\left(T_{g}-T_{s}\right) \cdot \Delta t
$$

The overall heat transfer coefficient is given by:

$$
U=\frac{1}{\frac{1}{\alpha_{c}+\alpha_{r}}+\frac{x}{\lambda}}
$$

The insulation thickness is $x$, convectional heat transfer coefficient $\alpha_{c}=25 \quad \mathrm{~W} / \mathrm{m}^{2} \cdot{ }^{0} \mathrm{~K}$, whereas for radiation heat transfer coefficient is $\alpha_{r}=\frac{5.67 \varepsilon}{T_{g}-T_{s}}\left[\left(\frac{T_{g}+273}{100}\right)^{4}-\left(\frac{T_{s}+273}{100}\right)^{4}\right]$ with same unit $\mathrm{W} / \mathrm{m}^{2} \cdot{ }^{0} \mathrm{~K}$, where $T_{g}$ and $T_{s}$ are the gas and steel temperature both inceasing as fire procceds. The surface emissivity is $\varepsilon=0.8$. Due to temperature dependency of radiation heat transfer coefficient $\alpha_{r}$, the underlying difference equations above, is strongly nonlinear and students have been taught about its numerical solution during the lectures.Part of the allocated data given to the student in which the name of students are removed are shown in figure 6 . They are thermal conductivity of the insulator $\lambda$ in $\mathrm{W} / \mathrm{m} \cdot{ }^{0} \mathrm{~K}$ and also section factor of the beam $A / V$ in $\mathrm{m}^{-1}$ in front of each student's name.

\begin{tabular}{|l|l|l|l|}
\hline Last Name & First Name & A/V in $\mathrm{m}^{-1}$ & $\lambda$ in W/(m* $\left.\mathrm{K}^{-1}\right)$ \\
\hline & & 100 & 0.1 \\
\hline & & 150 & 0.1 \\
\hline & & 140 & 0.11 \\
\hline & & 130 & 0.12 \\
\hline & & 110 & 0.13 \\
\hline & & 120 & 0.14 \\
\hline & 145 & 0.15 \\
\hline
\end{tabular}

Figure 6 : Sample of allocated data to individual students 
A master program is written by the assessor that contains all general data, and also accepts individual data for each student. For example if we enter the last row data in figure 6, i.e. $\lambda=0.15 \mathrm{~W} / \mathrm{m} \cdot{ }^{0} \mathrm{~K}$ and $A / V=145 \mathrm{~m}^{-1}$ which is allocated to a particular student, the master program will provide the minimum thickness $x_{\min }=20.28 \mathrm{~mm}$, then they will find the history of steel temperature duriing 30 minutes of fire according to table 1 :

\begin{tabular}{|l|l|l|l|l|l|l|}
\hline $\begin{array}{l}\text { Steel Temp } \\
\text { in }{ }^{0} \mathrm{C}\end{array}$ & $T_{s}=75$ & $T_{s}=130$ & $T_{s}=185$ & $T_{s}=240$ & $T_{s}=295$ & $T_{s}=350$ \\
\hline $\begin{array}{l}\text { Time in } \\
\text { minutes }\end{array}$ & $t_{I}=5.55$ & $t_{I I}=10.23$ & $t_{I I I}=14.90$ & $t_{I V}=19.70$ & $t_{V}=24.76$ & $t_{V I}=30.1$ \\
\hline
\end{tabular}

Table 1: History of steel temperature for minimum thickness $x_{\min }=20.28 \mathrm{~mm}$

Then students find the effect of insulation thickness on critical time, in case when pool fire stays longer than 30 minutes, that causes steel temperature rise up to $800{ }^{0} \mathrm{C}$ and in such situation structure collapses. The extra time taken (after 30 minutes) to reach $800{ }^{\circ} \mathrm{C}$ is called $\Delta t_{C I I I}$ or critical time in minimum thickness and it should be found in minutes. The students learn that if they choose different thicknesses, how that can effect on critical time or $\Delta t_{C}=t_{T_{s}=800^{\circ C}}-t_{T_{s}=350^{\circ C}}$ Then they need to summarize their finding in the table 2 like this:

\begin{tabular}{|l|l|l|l|l|l|l|}
\hline ratio & $\frac{x_{I}}{x_{\text {min }}}=0.6$ & $\frac{x_{I I}}{x_{\text {min }}}=0.8$ & $\frac{x_{I I I}}{x_{\text {min }}}=1$ & $\frac{x_{I V}}{x_{\text {min }}}=1.2$ & $\frac{x_{V}}{x_{\text {min }}}=1.4$ & $\frac{x_{V I}}{x_{\text {min }}}=1.6$ \\
\hline minutes & $\Delta t_{C I}=42.05$ & $\Delta t_{C I I}=55.38$ & $\Delta t_{C I I I}=68.75$ & $\Delta t_{C I V}=82.15$ & $\Delta t_{C V}=95.55$ & $\Delta t_{C V I}=108.1$ \\
\hline
\end{tabular}

Table 2: Critical in different insulation thicknesses, for $\lambda=0.15 \mathrm{~W} / \mathrm{m} \cdot{ }^{0} \mathrm{~K}$ and

$$
A / V=145 \quad \mathrm{~m}^{-1}
$$


Moreover, students can find the steel retention history. Retention is the ratio $\frac{\sigma_{Y T}}{\sigma_{Y 0}}$ in which $\sigma_{Y T}$ is steel yield stress at elevated temperature, whereas $\sigma_{Y 0}$ is steel yield stress at room temperature. For different insulation thicknesses students will find the retention history and summarize it in table 3.

\begin{tabular}{|l|l|l|l|l|l|}
\hline Extra time ratio & $\frac{\Delta t_{\mathrm{e}}}{\Delta t_{C I I I}}=0.2$ & $\frac{\Delta t_{\mathrm{e}}}{\Delta t_{C I I I}}=0.4$ & $\frac{\Delta t_{\mathrm{e}}}{\Delta t_{C I I I}}=0.6$ & $\frac{\Delta t_{\mathrm{e}}}{\Delta t_{C I I I}}=0.8$ & $\frac{\Delta t_{\mathrm{e}}}{\Delta t_{C I I I}}=0.98$ \\
\hline retention $\frac{x_{I I I}}{x_{\min }}=1$ & $\frac{\sigma_{Y T}}{\sigma_{Y 0}}=0.844$ & $\frac{\sigma_{Y T}}{\sigma_{Y 0}}=0.543$ & $\frac{\sigma_{Y T}}{\sigma_{Y 0}}=0.290$ & $\frac{\sigma_{Y T}}{\sigma_{Y 0}}=0.147$ & $\frac{\sigma_{Y T}}{\sigma_{Y 0}}=0.112$ \\
\hline retention $\frac{x_{I V}}{x_{\min }}=1.2$ & $\frac{\sigma_{Y T}}{\sigma_{Y 0}}=0.888$ & $\frac{\sigma_{Y T}}{\sigma_{Y 0}}=0.641$ & $\frac{\sigma_{Y T}}{\sigma_{Y 0}}=0.402$ & $\frac{\sigma_{Y T}}{\sigma_{Y 0}}=0.227$ & $\frac{\sigma_{Y T}}{\sigma_{Y 0}}=0.139$ \\
\hline retention $\frac{x_{V I}}{x_{\min }}=1.6$ & $\frac{\sigma_{Y T}}{\sigma_{Y 0}}=0.936$ & $\frac{\sigma_{Y T}}{\sigma_{Y 0}}=0.767$ & $\frac{\sigma_{Y T}}{\sigma_{Y 0}}=0.574$ & $\frac{\sigma_{Y T}}{\sigma_{Y 0}}=0.398$ & $\frac{\sigma_{Y T}}{\sigma_{Y 0}}=0.272$ \\
\hline
\end{tabular}

Table 3: Steel retention history in different insulation thicknesses, for $\lambda=0.15 \mathrm{~W} / \mathrm{m} \cdot{ }^{0} \mathrm{~K}$

$$
\text { and } A / V=145 \mathrm{~m}^{-1}
$$

Similarly by looking at the tables provided by the student with the same format, we find if he/she have found the correct results, and then prepare a quick feedback with more details, since there are 3 tables to check . It is not compulsory for students to write a computer program, because they are coming for a one year course with different academic background. However, most of them will be encouraged to learn a programing language, and majority of them used Excel spread sheet. Again they are allowed to discuss in group about the assignment, but each student need to prepare an individual report using his/her allocated data and submit it to the course web site. In postgraduate courses, individual students can spend several weeks to submit their work. From computational point of view, in EG5071 they need to solve a nonlinear differential equation, in which unsteady conduction, convection and radiation heat transfer in the fire are included in the model . 
In the lectures they have been taught to solve the governing equation by a simple time step method. They are free to use any language like MATLAB, Excel, etc.. The obtained results are very important and guides them to find the evacuation time when the structure is under fire. Moreover, they learn computational skills for Passive Fire Protection (PFP) of structures. The procedure is summarised by:

i. Find the thermal conductivity of the insulator $\lambda=? ? \mathrm{~W} / \mathrm{m} \cdot{ }^{0} \mathrm{~K}$ and also Area/Volume per unit length ratio of the beam $A / V=? ? \mathrm{~m}^{-1}$ from data list in front of student's name.

ii. The maximum thickness that can be chosen is $x_{\max }=\frac{c_{s} \rho_{s}}{2 c_{p} \rho_{p}} \frac{V}{A}$ such that lightweight insulation rules can be implemented. However the purpose of the assignment is, finding the minimum thickness of the insulation $x_{\text {min }}$

iii. Regarding convectional heat transfer assume that $\alpha_{c}=25 \mathrm{~W} / \mathrm{m}^{2} \cdot{ }^{0} \mathrm{~K}$ is constant, whereas for radiation heat transfer $\alpha_{r}=\frac{5.67 \varepsilon}{T_{g}-T_{s}}\left[\left(\frac{T_{g}+273}{100}\right)^{4}-\left(\frac{T_{s}+273}{100}\right)^{4}\right]$ with same unit $\mathrm{W} / \mathrm{m}^{2} \cdot{ }^{0} \mathrm{~K}$, where $T_{g}$ and $T_{s}$ are the gas and steel temperature both inceasing as fire procceds. The surface emissivity is $\varepsilon=0.8$.

iv. The incremental incease in steel temperature can be found from $\Delta T_{s}=\frac{U}{c_{s} \rho_{s}} \cdot \frac{A}{V} \cdot\left(T_{g}-T_{s}\right) \cdot \Delta t$ where $\Delta t$ is incremental time of your choice. Moreover $U$ is given by $U=\frac{1}{\frac{1}{\alpha_{c}+\alpha_{r}}+\frac{x}{\lambda}}$

There up to 40 students in this postgraduate course, the evaluation of the solution depends on the time step selection. Usually the students selected time steps, from $5 \mathrm{sec}$ up to 5 minutes. The students who are fluent in programming, choose small time step and they write the algorithms to find the minimum insulation thickness. The students who are struggling with programming, they choose 5 minutes step times and use trial and error method to find the minimum thickness. This enables the assessor to evaluate the solutions. The master computer program, enables the quick assessment of the assignment, such that feedback can be prepared 
in less than 15 minutes. In undergraduate course EG2503, the solution evaluation is very quick and there are above 300 students in the course. Assessor can look at the numbers in the figure 4, that is prepared by students and check the results with the results of master program and prepare the feedback in 3 minutes ( in average) .

Postgraduate assignments, are longer and the assessor should have extensive knowledge about the topic, not necessarily related to the educational skills, but academic knowledge. For example the author herein has research experience on design of structures in fire and explosion [13-14]. This paper is his first work on implementing computational knowledge in engineering education.

\section{Conclusions and discussions}

In this paper a semi-automatic digital assessment is introduced, in which for a particular assignment a master computer program is developed that can produce correct results for that assignment. Each student submits a report as a sole author, so they can practice independent thinking in problem solving. This is new and novel scheme which is currently the author uses in teaching at Aberdeen University. In the literature only automatic grading of multiple choice exams (not the short and long assignments herein) have been practiced substantially, and an example can be found in [15].

The advantage of the method, is in assessing the individual efforts by students, to stimulate their confidence. The assessment time does not increase significantly, because the assignment in mass courses are shorter. The master computer program makes the assessment faster and easier, such that a semi-automatic and detailed feedback for each student, can be provided in less than five minutes. The method is less faster for assessing long group assignments. In this case the assessment time will be reduced if peer review multiple choice questionnaire will be filled and submitted by the group. 
Both short assignment for mass undergraduate courses, and long assignment in normal postgraduate courses are discussed. It is demonstrated how the feedback details, depends on comparison of correct results with student's result. It is shown that in long practical assignment, postgraduate students with different academic background will be encouraged to learn a computer language for engineering calculations. In these type of assessment, group discussions and manual calculations, is not discouraged. However, students also relying on their own individual effort, apart from group discussions.

This method can be updated in future for any mass course with large number of student even if the assignment is very long. To fulfil this objective the level of artificial intelligence in the assessment should be increased . Thereby, enables the comparison between correct results and students result, and evaluation of the assignment based on the error , being done by computer as well. The technology is available and if number of students admitted to a course grows high (four figures ) fully automatic assessment will be pursued. 


\section{References:}

1) Palma, L. , Morrison, R.F., Enjeti, P. N. and. Howze, J.W. "Use of Web-Based Materials to Teach Electric Circuit Theory" ,IEEE Transactions on Education, vol. 48, no. 4, pp. 729-734. 2005.

2) Castier. M. and Amer. M.M.," XSEOS: An evolving tool for teaching chemical engineering thermodynamics", Education for Chemical Engineers, Vol. 6, e62-e70, 2011.

3) Fakas , G. J. Nguyen A.Y and Gillet, D. “ The Electronic Laboratory Journal: A Collaborative and Cooperative Learning Environment for Web-Based Experimentation", Computer Supported Cooperative Work, Vol. 14 pp. 189-216, 2005.

4) Swart, A.J. "Enhancing Students' Perception of Single-Sideband Suppressed-Carrier Principles by Using Cooperative and Computer-Based Learning”, Computer Application in Engineering Education, vol. 20, pp. 332-338, 2012.

5) Milentijevic, I. Vladimir Ciric, V. and Vojinovic, O. "Version control in project-based learning”, Computers \& Education, vol. 50 pp. 1331-1338, 2008.

6) Devendorf, M. , Lewis, K. , Simpson, T.W., Stone, R. B., and Regli, W.C. "Evaluating the Use of Digital Product Repositories to Enhance Product Dissection Activities in the Classroom" Transaction of ASME, Journal of Computing and Information Science in Engineering, Vol. 9 art. No. 041008-1, December 2009.

7) Hanson, J. H. and Williams, J.M. "Using Writing Assignments to Improve SelfAssessment and Communication Skills in an Engineering Statics Course”, Journal of Engineering Education, pp. 515-529, October 2008.

8) Rodriguez , S. Zamorano, J., Rosales, F. Dopico, A.G. and Pedraza, J.L. "A framework for lab work management in mass courses. Application to Low Level Input/ Output without hardware", Computers \& Education, vol. 48 pp. 153-170, 2007.

9) McMartin, F. McKenna, A. and Youssefi, K. "Scenario Assignments as Assessment Tools for Undergraduate Engineering Education", IEEE Transactions on Education, vol. 43, no. 2, pp. 111-119. 2000.

10) Malmi, L., Karavirta, V., Korhonen,A., Nikander, J. "Experiences on Automatically Assessed Algorithm Simulation Exercises with Different Resubmission Policies", ACM Journal on Educational Resources in Computing, Volume 5, Issue 3, p. 7, 2005. 
11)Zhan, Y. and Clark, J. A. "A search-based framework for automatic testing of MATLAB/Simulink models", Journal of Systems and Software, vol. 81 no. 2, pp. 262$285,2008$.

12) Char, B.W., Daulagala, I., Kandasamy, N., and Hewett, T.T., "Using automatic MATLAB program testing for a first-year engineering computation course", ASEE Annual Conference and Exposition, Conference Proceedings , June 2016.

13) Aleyaasin, M. Harrigan, J J ; Reid, S R.," Air-blast response of cellular material with a face plate : an analytical-numerical approach", International Journal of Mechanical Sciences, Vol. 91, no. 2 pp. 64-70, 2015.

14) Aleyaasin, M. "Protective and Blast Resistive Design of Post Tensioned Box Girders using Computational Geometry”, Advances in Civil Engineering, Vol. 2018, 4932987, 22.02. 2018.

15) Fisteus J. A. Pardo. A. and Garcia N.F., "Grading Multiple Choice Exams with LowCost and Portable Computer-Vision Techniques”, Journal of Science Education and Technology, Vol. 22 no. 4 pp. 560-571, 2013. 